\title{
Biotransformation using resting cells of Rhodococcus UKMP-5M for phenol degradation
}

\begin{abstract}
Phenol is a toxic compound that may be transformed into non-toxic compounds by the activity of microbial cells. The possibility of using biotransformation method for the degradation of phenol was studied using the whole cells of Rhodococcus UKMP-5M suspended in $250 \mathrm{~mL}$ shake flask with buffered liquid containing phenol. The cells of Rhodococcus UKMP-5M were produced by cultivation in Minimal Salt Medium (MSM) with the addition of phenol and/or glucose as carbon source. The biotransformation conditions to obtain the highest percentage of phenol degradation were as follows; $\mathrm{pH} 7.4,0.5 \mathrm{~g} / \mathrm{L}$ phenol in MSM as biotransformation medium, cells were produced by cultivation in MSM supplemented with $0.5 \mathrm{~g} / \mathrm{L}$ phenol and the optimal cell concentration was $10 \%$. The phenol degradation rate obtained in biotransformation using Rhodococcus UKMP-5M cells correlated well with phenol hydroxylase activity. The highest percentage of phenol degradation in biotransformation using suspended cells of Rhodococcus UKMP-5M was only up to $89 \%$, which was slightly lower than those obtained in growing cell system (98\%).
\end{abstract}

Keyword: Biotransformation; Phenol hydroxylase; Biodegradation of phenol; Rhodococcus UKMP-5M 